Abstracta Iranica Abstracta Iranica

Revue bibliographique pour le domaine irano-aryen

Volume 30 | 2010

Comptes rendus des publications de 2007

\title{
Etymological Dictionary of the Iranian Verb. Leiden, Boston, Brill, 2007, xxii + 600 p. (Leiden Indo- European Etymological Dictionary Series, 2)
}

\section{Samra Azarnouche}

\section{(2) OpenEdition}

Journals

Édition électronique

URL : http://journals.openedition.org/abstractairanica/37543

DOI : 10.4000/abstractairanica.37543

ISSN : 1961-960X

Éditeur :

CNRS (UMR 7528 Mondes iraniens et indiens), Éditions de l'IFRI

Édition imprimée

Date de publication : 8 avril 2010

ISSN : 0240-8910

Référence électronique

Samra Azarnouche, «Etymological Dictionary of the Iranian Verb. Leiden, Boston, Brill, 2007, xxii + 600 p. (Leiden Indo-European Etymological Dictionary Series, 2) », Abstracta Iranica [En ligne], Volume 30 | 2010, document 13, mis en ligne le 08 avril 2010, consulté le 27 septembre 2020. URL : http:// journals.openedition.org/abstractairanica/37543; DOI : https://doi.org/10.4000/abstractairanica. 37543

Ce document a été généré automatiquement le 27 septembre 2020.

Tous droits réservés 


\title{
Etymological Dictionary of the Iranian Verb. Leiden, Boston, Brill, 2007, xxii +600 p. (Leiden Indo-European Etymological Dictionary Series, 2)
}

\author{
Samra Azarnouche
}

1 Cet ouvrage, qui comble une des graves lacunes de l'étymologie iranienne, peut être considéré comme un point de jonction d'une part entre les indianistes et les iranisants, et d'autre part entre les spécialistes des langues iraniennes anciennes et ceux des langues modernes.

2 Le matériel présenté se limite aux racines verbales attestées en proto-iranien - relativement hermétiques à la contamination et à l'emprunt-, même celles qui étaient originalement nominales, ainsi que leur continuation. Il exclut en revanche la reconstruction de racines qui sont représentées en (indo-)iranien uniquement par une continuation nominale.

3 Afin de tracer la provenance d'une racine, celle-ci a tout d'abord été comparée avec les formes sanscrites attestées suivant l'ouvrage de référence de Mayrhofer, l'EWAia (1952-2001), puis l'origine indo-européenne a été analysée à l'aide du LIV (Rix, 2001) et du IEW (Pokorny, 1959).

4 Ce dictionnaire se veut « un point de départ pour des recherches futures » (p. xi) et l'A. n'est pas sans savoir que certaines racines ou certaines formes ou entrées peuvent être contestées et sujettes à débat.

5 Les entrées sont organisées par ordre des racines proto-iraniennes reconstruites, au degré plein et en prenant compte des laryngales. Sous chacune d'elles, apparaissent les attestations de la racine dans les langues iraniennes, celles-ci classées par ordre d'ancienneté et d'importance, et suivie d'une référence bibliographique. La précision du travail est poussée jusqu'à faire apparaître pour certaines langues les formes des 
différents thèmes verbaux attestés, des exemples de formes conjuguées avec référence au texte, ainsi que les emplois avec différents préverbes.

6 Puis suivent enfin, les équivalents sanscrits (si attestés), proto-indo-européens et indoeuropéens. L'entrée se termine par des références bibliographiques complémentaires.

7 Lorsqu'une racine recouvre un champ sémantique trop vaste ou trop diversifié selon les langues, l'A. fait le choix de la représenter dans deux voire trois entrées différentes en regroupant sous chacune les significations apparentées, ou bien, il choisit de reconstruire une seule racine primordiale capable de recouvrir toute la diversité sémantique.

8 Un index indispensable de près de 100 pages (pp. 505-600) clôt cet ouvrage, dont un index anglais-iranien. L'index principal regroupe sous chacune des 170 langues (ellesmêmes classées pages 505-507), tous les termes (verbes ou autres) employés dans le corps du dictionnaire.

9 Ce dictionnaire qui prend en compte toute la documentation jusqu'en 2006, s'avère un outil indispensable tant aux spécialistes qu'aux étudiants.

INDEX

Thèmes : 2.1. Langues anciennes

\section{AUTEURS}

SAMRA AZARNOUCHE

Paris 